\title{
Positive physiological effects of touching sugi (Cryptomeria japonica) with the sole of the feet
}

\author{
Harumi Ikei ${ }^{1,2}$ (D) and Yoshifumi Miyazaki ${ }^{*}$ (1)
}

\begin{abstract}
In Japanese households, it is customary to walk barefoot on wood floors. This study sought to clarify the physiological effects produced via tactile application of sugi (Cryptomeria japonica) to the sole of the feet, using the brain and autonomic nervous activities as indicators. Twenty-seven female university students (mean age, 21.9 \pm 1.9 years) participated in this study. Oxy-hemoglobin (oxy-Hb) concentrations in the prefrontal cortex were determined using near-infrared time-resolved spectroscopy. High frequency (HF), denoted parasympathetic nervous activity, and low frequency (LF)/HF indicated sympathetic nervous activity; both were measured using heart rate variability. The wooden material was unpainted sugi wood with two different finishes uzukuri brushing or sanding. A similarly sized marble plate served as a control. The sole of the feet of each participant touched each material for $90 \mathrm{~s}$. The results found that the uzukuri wood significantly decreased oxy-Hb concentration in the left prefrontal cortex compared with touching the marble. Furthermore, compared to before contact, the uzukuri wood showed significantly decreased oxy-Hb concentrations in the right prefrontal cortex, increased In(HF), and decreased the In(LF/HF) ratio. Moreover, the contact with sanded wood significantly decreased oxy-Hb concentrations in the right prefrontal cortex compared with before contact. Thus, it is concluded that tactile application of sugi to the sole of the feet induced physiological relaxation.
\end{abstract}

Keywords: Japanese cedar, Tactile, Prefrontal cortex activity, Autonomic nervous activity, Near-infrared spectroscopy, Heart rate variability, Semantic differential method, Profile of mood states, Physiological relaxation, Habitability

\section{Introduction}

Modern society today is stressful [1,2]; thus, there is a growing interest in the relaxation effects of naturederived stimuli $[3,4]$. Wood is a typical nature-derived material that has long been used in houses and furniture in Japan. In recent years, attention has been focused on the effects of wood on human physiological responses, and scientific data have been accumulated primarily by Japanese research teams [5]. In 1992 Miyazaki et al. [6] first reported that Taiwan cypress oil lowered systolic

\footnotetext{
*Correspondence: ymiyazaki@faculty.chiba-u.jp

${ }^{1}$ Center for Environment, Health and Field Sciences, Chiba University,

6-2-1 Kashiwa-no-ha, Kashiwa, Chiba 277-0882, Japan

Full list of author information is available at the end of the article
}

blood pressure. Subsequent to this study, there have been multiple reports regarding olfactory stimulation [7-10]. Conversely, very few reports regarding tactile stimuli were investigated. In response to this, recent research has begun to focus on the effects of tactile stimulation from wood by using the prefrontal cortex and autonomic nerve activity as indexes [11-14]. The physiological effects of palm contact with wood have been investigated for sugi (Japanese cedar, Cryptomeria japonica) [11], hinoki (Japanese cypress, Chamaecyparis obtusa) [12], and white oak (Quercus alba) [13, 14]. Touching with the palm of the hand in the sitting position for $90 \mathrm{~s}$ reduced prefrontal cortex activity, increased parasympathetic nervous activity, and decreased the heart rate compared to other types of building materials [11-13] and coated wooden
SpringerOpen

(c) The Author(s) 2020. This article is licensed under a Creative Commons Attribution 4.0 International License, which permits use, sharing, adaptation, distribution and reproduction in any medium or format, as long as you give appropriate credit to the original author(s) and the source, provide a link to the Creative Commons licence, and indicate if changes were made. The images or other third party material in this article are included in the article's Creative Commons licence, unless indicated otherwise in a credit line to the material. If material is not included in the article's Creative Commons licence and your intended use is not permitted by statutory regulation or exceeds the permitted use, you will need to obtain permission directly from the copyright holder. To view a copy of this licence, visit http://creativeco mmons.org/licenses/by/4.0/. 
materials [14]; thus indicating a state of physiological relaxation for the participants.

Wood is often used as a flooring material. It is necessary to clarify the influence of foot contact with wood, because it is customary to walk barefoot indoors in Japan. In addition, the "uzukuri finish (brushing finish)" is one of the traditional surface finishing methods in Japan. "Uzukuri finish" is a finishing method for coniferous materials such as sugi or hinoki. This finishing method involves scraping off the soft earlywood part with a brush and leaving an embossed hard latewood part exposed [15]. This processing makes the wood-grain standout and emphasizes the feel specific to this wood. We investigated the effects of sole of the feet contact with the uzukuri finished hinoki wood on brain activity and autonomic nervous activity in the previous study [16]. As a result, contact with uzukuri finish hinoki for $90 \mathrm{~s}$ decreased the prefrontal cortex activity, increased parasympathetic nervous activity, and decreased sympathetic nervous activity compared to the marble, control, which is a common building material.

Sugi is the most representative wood in Japan, and there is a growing interest in the relaxing effect of this wood. According to the Ministry of Agriculture, Forestry, and Fisheries "Wood Supply and Demand Report [17], sugi wood accounts for approximately $60 \%$ $\left(11,848,000 \mathrm{~m}^{3}\right)$ of the total of $20,660,000 \mathrm{~m}^{3}$ wood used in 2016. In a previous study on sugi, Sakuragawa et al. [18] examined the effect on blood pressure. As a result, 13 male college students who made palm contact with the sugi showed a decrease in blood pressure except for a temporary change immediately following contact. However, no study has evaluated yet the physiological effects of touching uzukuri finish sugi wood with the sole of the feet.

This study aimed to clarify the physiological effects of tactile stimulation with sugi to the sole of the feet. To evaluate physiological responses, we measured prefrontal cortex activity in terms of oxy-hemoglobin (oxy- $\mathrm{Hb}$ ) concentrations in the left and right prefrontal cortices using near-infrared time-resolved spectroscopy (TRS), and sympathetic and parasympathetic nervous activities assessed in terms of heart rate variability (HRV) and the heart rate.

\section{Materials and methods Participants}

Considering that we want to continue the previous studies [11-14, 16], a total of 27 female Japanese university students (mean age: $21.9 \pm 1.9$ years) were included in the current study. None of the participants reported any physiological or psychiatric disorders in their personal histories, and all were non-smokers. Further, none of the participants were menstruating on the day of the experiment. All participants provided written informed consent to participate after being informed about the study's aims and procedures. This study was conducted in accordance with the Declaration of Helsinki and adhered to the regulations set by the Ethics Committee of the Center for Environment, Health, and Field Sciences, Chiba University, Japan (Project Identification Code Number 34). This study is registered in the University Hospital Medical Information Network of Japan (Unique ID issued by UMIN: UMIN000032808).

\section{Tactile stimulation}

Sugi (Japanese cedar, Cryptomeria japonica) wood grown in the Miyazaki Prefecture, Japan, was used as the base material for this experiment. Five wooden laminae without vertical joints $(600 \times 120 \times 20 \mathrm{~mm})$ were bonded together along their width using a water-based polymer isocyanate adhesive. A second bonding was made using sugi plywood $(600 \times 600 \times 24 \mathrm{~mm})$ to prevent bending; the total thickness of the resultant finished product was $44 \mathrm{~mm}$. The surface was uncoated and finished via either (1) brushing using a stainless-steel wire brush (hereafter referred to as "uzukuri wood" Fig. 1a), or (2) sanding using an abrasive-band machine (hereafter referred to as "sanded wood" Fig. 1b). A marble slab $(600 \times 600 \times 20 \mathrm{~mm})$ was used as the control material, because its properties are substantially different from those of wood. Moreover, marble was used as a comparative sample in previous studies [11-13, 16]. In this study, it was placed on a piece of cedar plywood of the same size as that of the plywood bonded to sugi. The surface was processed by buffing (Fig. 1c). This buffed marble sample is hereafter referred to as "marble". All materials were stored at room temperature. The physical properties of the materials are listed in Table 1.

\section{Study protocol}

Physiological effects were measured in a chamber with an artificial climate which has a soundproof function maintained at $24{ }^{\circ} \mathrm{C}, 50 \%$ relative humidity, and 230-lux illumination.

Figure 2 depicts the experimental setup, whereas Fig. 3 depicts the experimental protocol. Sensors for the physiological measurements were attached to each participant's forehead and chest. After receiving information about the overall measurement flow, the participants initially trialed the test procedure by placing their feet on a practice material (plastic board) utilizing the same procedure to be followed for the actual measurements. The participants rested with their eyes closed for $60 \mathrm{~s}$ (Fig. 2a). By raising the sample using a scissor lift (Fig. 2b), the participants passively touched the samples 


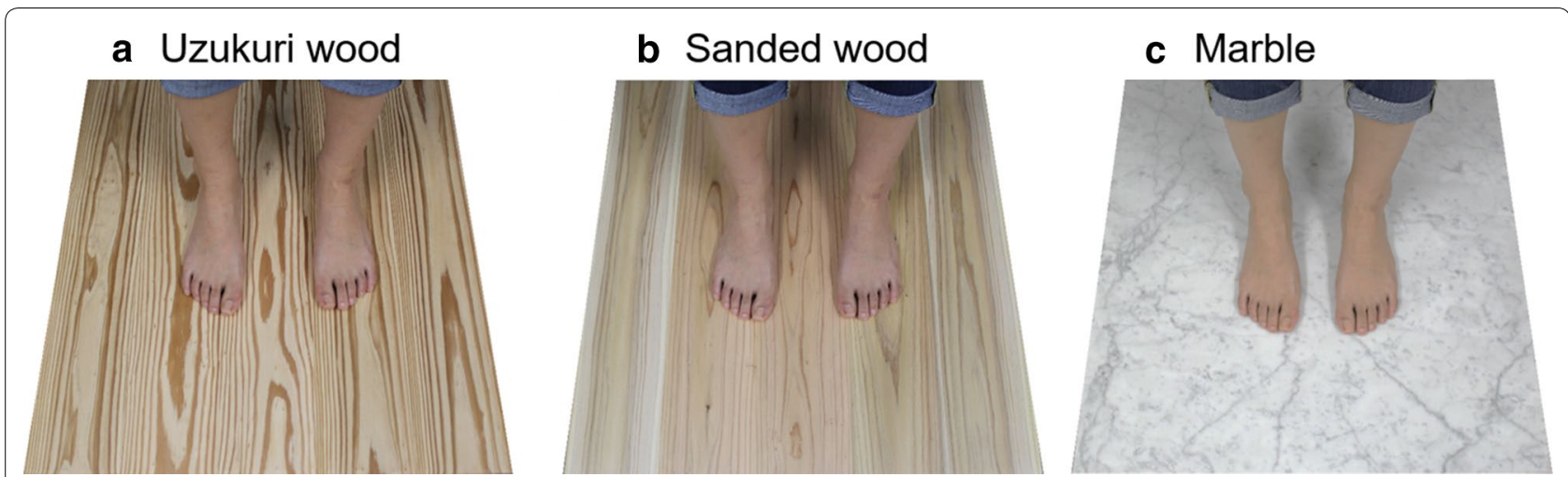

Fig. 1 Materials used in the tactile experiment. a Uzukuri wood: the surface of Japanese cedar material was uncoated and finished by brushing with a stainless-steel wire brush. $\mathbf{b}$ Sanded wood: the surface of Japanese cedar material was uncoated and finished by sanding it with an abrasive-band machine. c Buffed marble: the control

Table 1 Details of the samples

\begin{tabular}{llllc}
\hline Material $^{\mathbf{a}}$ & $\boldsymbol{h}(\mathbf{m m})$ & $\boldsymbol{\lambda}[\mathbf{W} /(\mathbf{m ~ K})]^{\mathbf{b}}$ & $\mathbf{R a}(\boldsymbol{\mu m})^{\mathbf{c}}$ & $\mathbf{R z}(\boldsymbol{\mu m})^{\mathbf{c}}$ \\
\hline Uzukuri wood & $20(+$ SP 24) & 0.106 & 52.38 & 234.91 \\
Sanded wood & $20(+$ SP 24) & 0.120 & 3.65 & 35.46 \\
Marble & $20(+$ SP 24) & 1.947 & 0.16 & 3.22 \\
\hline
\end{tabular}

The evaluation length was $50 \mathrm{~mm}$. The cut-off value was $8 \mathrm{~mm}$. The central portion of the samples was measured five times with $50-\mathrm{mm}$ spacing, and the average value was calculated

$h$ Thickness of the material, $\lambda$ thermal conductivity, $R a$ arithmetic average roughness, $R z$ maximum height roughness, $S P$ structural plywood

a The samples were cut out from the center part of the material to a size of $300 \times 300 \mathrm{~mm}$, and their physical properties were assessed. Note that the wood samples were used with the cedar plywood attached. ${ }^{b}$ A heat flow meter (HFM 436 Lambda; NETZSCH, Selb, Germany), tuned according to ASTM C518-10 [19] and ISO8310 [20], was used. The direction of heat flow was vertically downward. The temperatures of the high- and low-temperature heat plates were $35^{\circ} \mathrm{C}$ and $15^{\circ} \mathrm{C}$, respectively. The thermal conductivity at an average material temperature of $25^{\circ} \mathrm{C}$ was calculated. ${ }^{\mathrm{C}}$ To determine the roughness of the material, a contact surface roughness profilometer (SE3500; Kosaka Laboratory Ltd., Tokyo, Japan) with a diamond stylus was used

with their sole of the feet while keeping their eyes closed for $90 \mathrm{~s}$ (Fig. 2c). The contact was ended by lowering the sample with the scissor lift (Fig. 2a). The researcher then set up another sample for the next measurement, covered the sample with a cloth so that the subjects could not see the sample, and then told the participants to open their eyes. Next, the subjective evaluation tests of the participants were performed. Stimulation with the subsequent materials was performed after a rest period of approximately $5-7 \mathrm{~min}$. The materials were presented in a counterbalance to eliminate any order effects, such as adaptation and fatigue, caused by the sequence of tactile stimulation.

\section{Near-infrared time-resolved spectroscopy (TRS)}

Near-infrared time-resolved spectroscopy (TRS), which is one of the methods of near-infrared spectroscopy (NIRS), was used as an index for the prefrontal cortex activity. The prefrontal cortex is a part of the brain that is responsible for higher-order judgments, such as problem-solving and decision-making. It has been reported that NIRS signals were highly correlated with functional magnetic resonance imaging measurements by a previous study using simultaneous NIRS (placing NIRS probes over the frontal brain region including the prefrontal region) and functional magnetic resonance imaging during a battery of cognitive tasks [21]. Thus, NIRS enables the detection of brain activity in the prefrontal cortex region. Sensors were mounted on the participant's forehead, and the oxy-Hb concentrations in the prefrontal cortex were measured using the TRS-20 system (Hamamatsu Photonics K.K., Shizuoka, Japan). Changes in blood flow (rCBF) associated with the local nerve activity in the brain were correlated with changes in the oxy- $\mathrm{Hb}$ and total $\mathrm{Hb}$ concentrations in the near-infrared spectroscopy measurements [22-24]. Changes to the oxy-Hb concentration measured by TRS reflected the prefrontal activity via a sensor attached to the forehead [25-27]. It has been reported that oxy- $\mathrm{Hb}$ concentrations in the prefrontal cortex are reduced by pleasant emotions and increased by unpleasant emotions [28]. The oxy-Hb concentrations in the left and right prefrontal cortices were measured for $30 \mathrm{~s}$ before (pre-measurement) and during the 90-s duration in which the participants' sole of the feet touched the materials (post-measurement). All data were transformed by linear interpolation to every $1 \mathrm{~s}$ because their sampling intervals were approximately 1.07$1.19 \mathrm{~s}$. In addition, post-measurement values (at every second) were calculated as the differences between the 


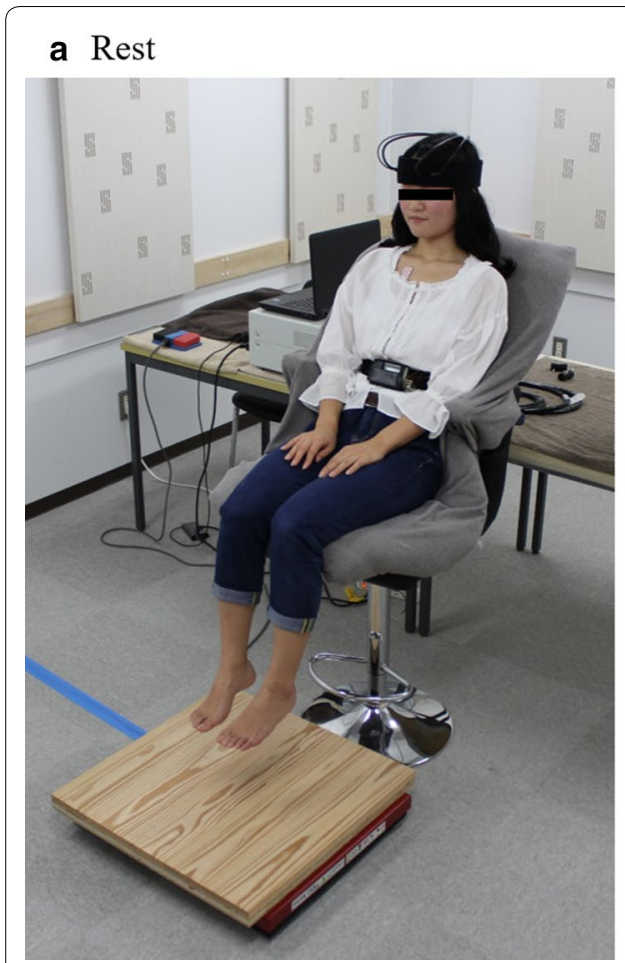

b Elevating the material

c Contact with material
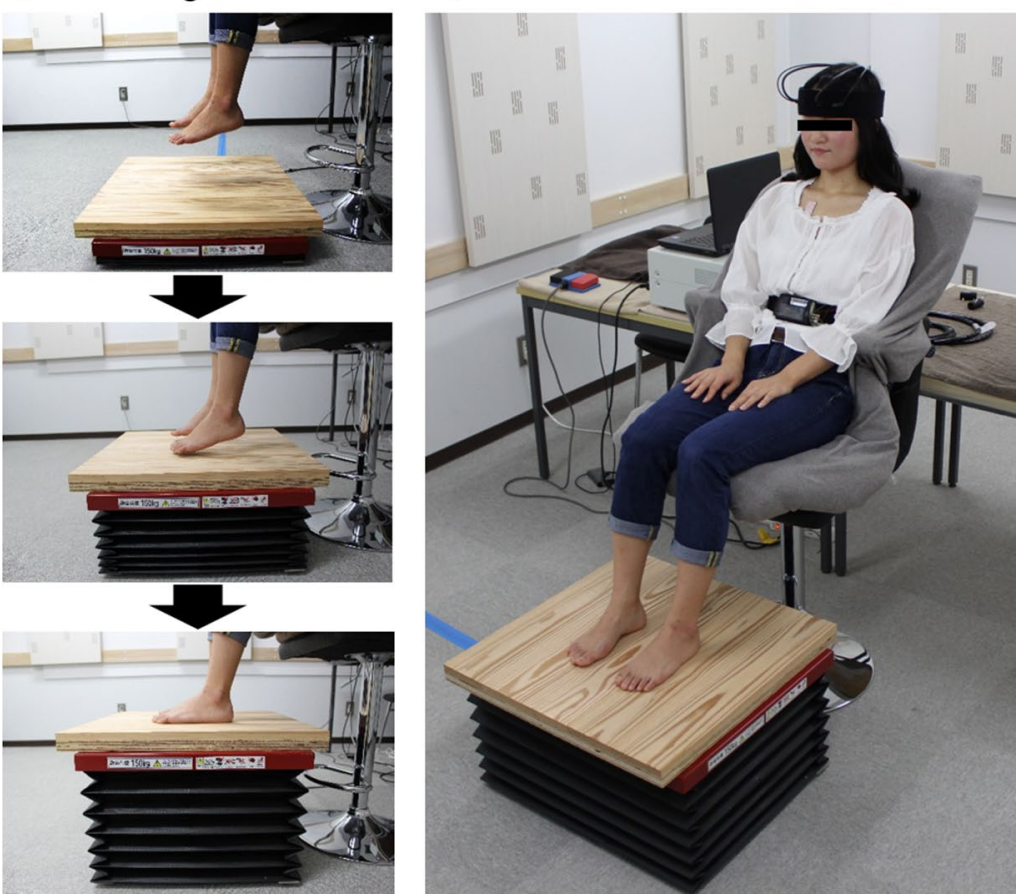

Fig. 2 Experimental scene. a Participants rested with their eyes closed for 60 s. b The sample was elevated using a scissor lift. c Participants passively contacted with material while keeping their eyes closed for $90 \mathrm{~s}$

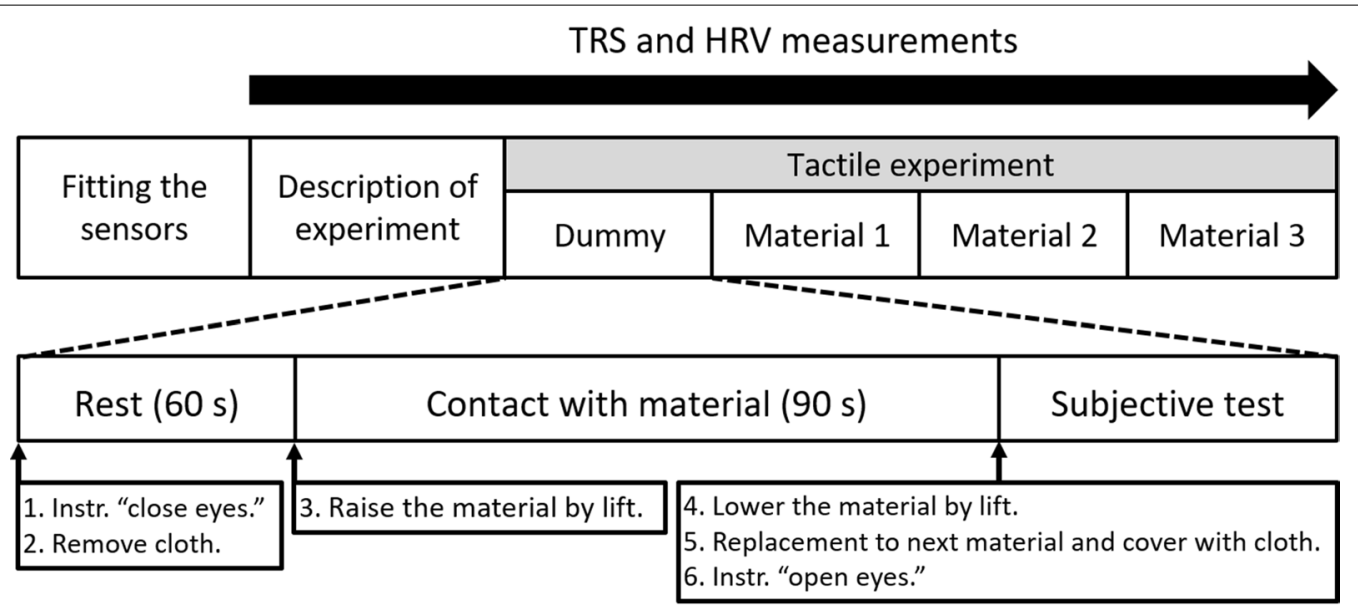

Fig. 3 Procedure for the entire experiment. The order of contact with the material was counterbalanced. TRS near-infrared time-resolved spectroscopy, HRV heart rate variability, Instr instruction to the participants

pre-measurement values (mean $30 \mathrm{~s}$ ). In addition, the total hemoglobin (total $\mathrm{Hb}$ ) and deoxygenated hemoglobin (deoxy-Hb) concentrations were measured and calculated as described for the oxy-Hb concentration.

\section{Heart rate variability (HRV) and heart rate}

HRV and heart rate were employed as indicators of autonomic nervous activity. HRV was analyzed for the periods between consecutive $R$ waves $(R-R$ intervals, $\mathrm{RRI}$ ), as measured by a portable electrocardiograph (Activtracer AC-301A; GMS, Tokyo, Japan) [29, 30]. This device uses a 3-lead electrocardiogram (Lead II) to 
perform necessary measurements. High frequency (HF; $0.15-0.40 \mathrm{~Hz}$ ) and low frequency (LF; 0.04-0.15 Hz) power level components of HRV were calculated using the maximum entropy method (MemCalc/Win; GMS, Tokyo, Japan) [31, 32]. The HF power indicated parasympathetic nervous activity, whereas the LF/HF power ratio indicated sympathetic nervous activity $[29,33]$. The natural logarithmic values for $\mathrm{HF}, \ln (\mathrm{HF})$ power and the LE/ $\mathrm{HF}, \ln (\mathrm{LF} / \mathrm{HF})$ power ratios were employed to normalize the HRV parameters across participants [34]. The mean HRV and heart rate were calculated for $90 \mathrm{~s}$ during which the participants' soles were in contact with each material. Average values for the pre- and post-measurement values for $\ln (\mathrm{HF})$ and $\ln (\mathrm{LF} / \mathrm{HF})$ were calculated.

The HRV power spectra were also used to estimate the participant's respiratory frequency [35]. Respiratory changes influenced the HRV data, with heart rate generally increasing during inspiration and decreasing during expiration [36, 37]; thus, the respiratory rate could be estimated from the dominant frequency of the HF component, found by detecting the maximal power of the HF component. To detect the peak frequency of the HF component, the model order for the spectral analysis was chosen from 8 to 11; however, the ninth order was used in principle. Since respiratory changes affect HRV data, respiratory frequencies were statistically compared between the mean values over the 90-s contact period for each material and pre- and post-measurement by paired t-tests.

\section{Psychological measurements}

The modified semantic differential (SD) method [38] and the short version of the Profile of Mood States Second Edition (POMS2) [39-42] were used to evaluate the psychological effects produced by the tactile stimulation from the materials. In the modified SD methods, seven pairs of adjectives from 13 scales of adjectives were assessed "comfortable-uncomfortable"; "relaxed-awakening"; "natural-artificial"; "warm-cold"; "uneven-flat"; "dry-moist"; and "soft-hard". POMS2 questionnaire was used to evaluate the mood states from the scores for Tension-Anxiety (T-A), Depression-Dejection (D-D), Anger-Hostility (A-H), Fatigue-Inertia (F-I), Confusion-Bewilderment (C-B), Vigor-Activity (VA), and Friendliness (F). The total mood disturbance (TMD) score was calculated using this formula: [(TA) $+(\mathrm{D}-\mathrm{D})+(\mathrm{A}-\mathrm{H})+(\mathrm{F}-\mathrm{I})+(\mathrm{C}-\mathrm{B})-(\mathrm{V}-\mathrm{A})]$. The TMD score reflects the general mood state, whereby a higher score denotes negative feelings of the participant and vice versa. The POMS2 is a well-established means sure of psychological distress derived from factor analysis that has been shown to possess high levels of reliability and validity. In order to reduce the burden on the participants, a shortened Japanese version of POMS2 with 35 questions was used for this study.

\section{Statistical analysis}

The Statistical Package for the Social Sciences software (v21.0; IBM Corp., Armonk, NY, USA) was used for all of the statistical analyses. In all cases, $p<0.05$ was considered statistically significant.

Paired t-tests were applied to analyze (1) differences in the physiological indices between the three materials (uzukuri wood vs. marble, sanded wood vs. marble, uzukuri wood vs. sanded wood) and (2) comparison before and after contact (pre- vs. post-measurement) for each material. Wilcoxon signed-rank tests were applied to analyze differences in the psychological indices between the three materials.

Holm correction was applied thrice to adjust the family-wise error rate in the comparison between stimuli [43]. The test statistics were calculated for all comparisons, and $P$-values were obtained. Hypotheses were arranged in descending order based upon $P$-values. Since the total number of tests was three, the minimum $P$ value was compared with the significance level $\alpha=0.05 / 3$. If the result of the aforementioned test was significant, then the second smallest $P$-value was compared with $\alpha=0.05 / 2$. In the same manner, proceeding in descending order based on the $P$-values, reduced the denominator by one, for each test. If a non-significant comparison is found, then the test is terminated at that point. For subsequent hypotheses, even if there was a $P$-value lower than the significance level at that step, we will hold all of the conclusions, and conclude that there was no difference found.

\section{Results}

\section{Physiological effects}

TRS

Figure 4 shows the time-dependent changes in the oxy$\mathrm{Hb}$ concentration per second in the right and left prefrontal cortex during contact with the uzukuri wood, sanded wood, and marble materials. The oxy-Hb concentrations in the left prefrontal cortex showed a transient decrease immediately following contact with all three of the materials. The oxy- $\mathrm{Hb}$ concentrations during contact with the uzukuri wood were lower than the concentrations before tactile stimulation and generally took $81 \mathrm{~s}$ to return to this state (Fig. $4 \mathrm{a}$, line of brown). The oxy-Hb concentrations during contact with the sanded wood returned to the pre-measurement value at $5 \mathrm{~s}$, but decreased again at $18 \mathrm{~s}$. Following this, it returned to the pre-measurement value at $52 \mathrm{~s}$ and then continued to rise 


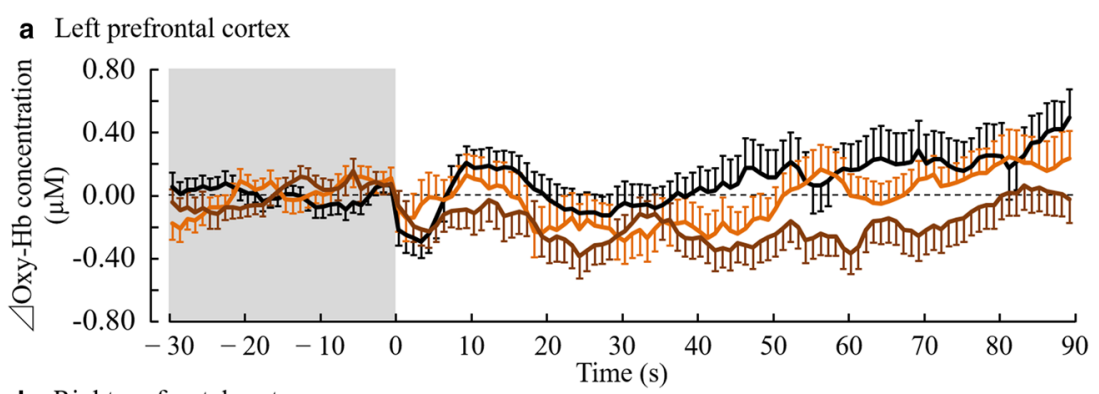

b Right prefrontal cortex

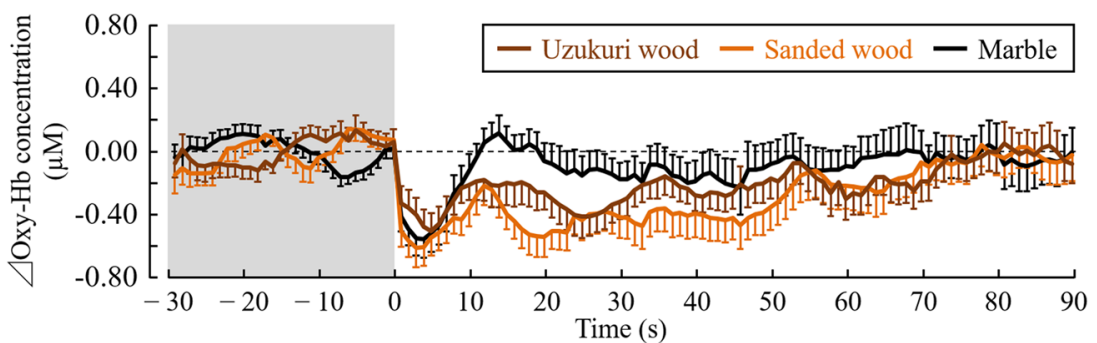

Fig. 4 Changes in the left and right prefrontal cortex activities during sole of the feet contact with the materials for every second over a $90-s$ period. $\mathbf{a} \mathrm{Oxy}-\mathrm{Hb}$ concentrations in the left prefrontal cortex. $\mathbf{b} \mathrm{Oxy}-\mathrm{Hb}$ concentrations in the right prefrontal cortex. $n=27$, mean \pm standard error (SE)

(Fig. 4a, line of orange). The oxy-Hb concentrations during contact with the marble returned to the pre-measurement value at $7 \mathrm{~s}$, but decreased again at $22 \mathrm{~s}$. Then, it returned to the pre-measurement value at $37 \mathrm{~s}$ and then continued to rise (Fig. 4a, line of black). The oxy-Hb concentrations in the right prefrontal cortex showed a transient decrease immediately after contact for all three materials. A similar trend occurs in the left prefrontal cortex (Fig. 4b). The oxy-Hb concentrations during contact with the uzukuri and the sanded wood materials both produced a lower value than that prior to contact measurement and then returned to the pre-measurement value at $78 \mathrm{~s}$ and $77 \mathrm{~s}$, respectively (Fig. 4b, line of brown and orange). The oxy-Hb concentrations during contact with the marble returned to the pre-measurement value at $11 \mathrm{~s}$, but decreased again at $20 \mathrm{~s}$. Then, it returned to the pre-measurement value at $52 \mathrm{~s}$ and continued at similar values to before the contact (Fig. 4b, line of black).

The overall mean for the oxy-Hb concentrations (calculated as the measurement after the stimulus minus the measurement before the stimulus) in the left and right prefrontal cortices during contact with the sole of the feet for each subject at $90 \mathrm{~s}$ are shown in Fig. 5a, b, respectively. The oxy- $\mathrm{Hb}$ concentrations in the left prefrontal cortex were $-0.19 \pm 0.10,-0.03 \pm 0.11$, and $0.09 \pm 0.12 \mu \mathrm{M}$ during contact with uzukuri wood, sanded wood, and marble, respectively. The oxy-Hb concentrations were significantly lower while touching uzukuri wood compared with the control (Fig. 5a, $p<0.05)$. However, no significant difference was observed in the comparison before and after contact with each of the three materials. Incidentally, the mean baseline oxy$\mathrm{Hb}$ concentrations during the $30 \mathrm{~s}$ before contact did not significantly differ between each of the three materials (43.64 $\pm 0.90 \mu \mathrm{M}$ for uzukuri wood, $44.48 \pm 0.91 \mu \mathrm{M}$ for the sanded wood, $44.65 \pm 0.98 \mu \mathrm{M}$ for marble; $p>0.05$ ). The oxy-Hb concentrations in the right prefrontal cortex were $-0.21 \pm 0.09,-0.29 \pm 0.09$, and $-0.11 \pm 0.10 \mu \mathrm{M}$ during contact with the uzukuri wood, sanded wood, and marble, respectively. The oxy-Hb concentrations were significantly lower while in contact with the uzukuri and sanded material compared with prior to contact (Fig. 5b, $p<0.05)$. However, no significant difference was observed in the comparison before and after contact with marble. There were no significant differences found for oxy$\mathrm{Hb}$ between the three materials. Incidentally, the mean baseline oxy-Hb concentrations during the $30 \mathrm{~s}$ prior to contact did not significantly differ between each of the three materials $(43.26 \pm 1.03 \mu \mathrm{M}$ for uzukuri wood, $43.05 \pm 1.07 \mu \mathrm{M}$ for sanded wood, $42.91 \pm 1.10 \mu \mathrm{M}$ for marble; $p>0.05)$.

\section{HRV}

The $\ln (\mathrm{HF})$ values were $6.04 \pm 0.14 \mathrm{lnms}^{2}$ during contact with the uzukuri wood, $5.98 \pm 0.14 \mathrm{lnms}^{2}$ during contact with the sanded wood, and $5.93 \pm 0.16 \mathrm{lnms}^{2}$ during contact with the marble. The $\ln (\mathrm{LF} / \mathrm{HF})$ was $-0.45 \pm 0.16$ during contact with the uzukuri wood, $-0.20 \pm 0.18$ 
a Left prefrontal cortex

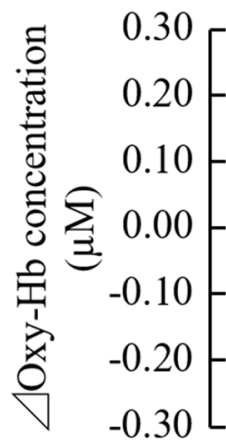

b Right prefrontal cortex

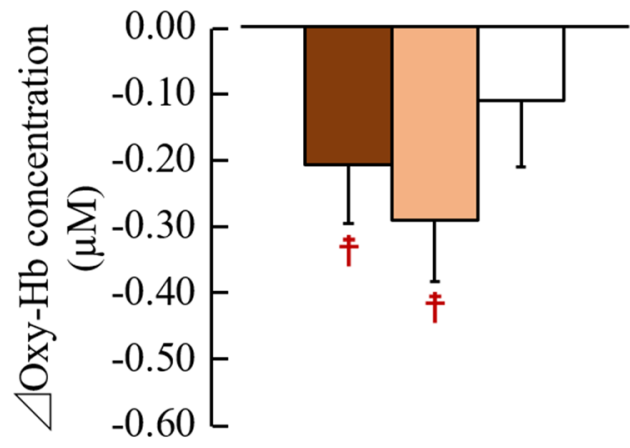

\section{口Uzukuri wood $\square$ Sanded wood $\square$ Marble}

Fig. 5 Overall mean for the left and right prefrontal cortex activities during sole of the feet contact with the materials. a Oxy-Hb concentrations in the left prefrontal cortex. $n=27$, mean $\pm S E,{ }^{*} p<0.05$ (brushed wood vs. marble) as determined using a paired t-test with Holm correction. $\mathbf{b}$ $\mathrm{Oxy}-\mathrm{Hb}$ concentrations in the right prefrontal cortex. $n=27$, mean $\pm \mathrm{SE},+p<0.05$ (pre-measurement vs. post-measurement value) as determined using a paired t-test

during contact with the sanded wood, and $-0.22 \pm 0.19$ during contact with the marble.

Because there was a significant difference found in the breathing frequency between the uzukuri wood and the marble $(p=0.014)$, no comparison was made between these materials in HRV. Conversely, there were no significant differences found in the breathing frequency before and after the contact, so the statistical analysis in HRV was performed. $\ln (\mathrm{HF})$ was significantly increased by tactile stimulation with the uzukuri wood compared with the pre-measurement value $\left(5.83 \pm 0.16 \mathrm{lnms}^{2}\right.$ for pre-measurement value, $6.04 \pm 0.14 \mathrm{lnms}^{2}$ for post-measurement value; Fig. $6 \mathrm{a}, p<0.05)$. There were no significant differences found in the sanded wood $(5.87 \pm 0.17$ $1 \mathrm{nms}^{2}$ for pre-measurement, $5.98 \pm 0.14 \mathrm{lnms}^{2}$ for postmeasurement) and marble $\left(5.95 \pm 0.19 \mathrm{lnms}^{2}\right.$ for premeasurement, $5.93 \pm 0.16 \mathrm{lnms}^{2}$ for post-measurement) between, before, and after contact. Incidentally, the a Parasympathetic nervous activity

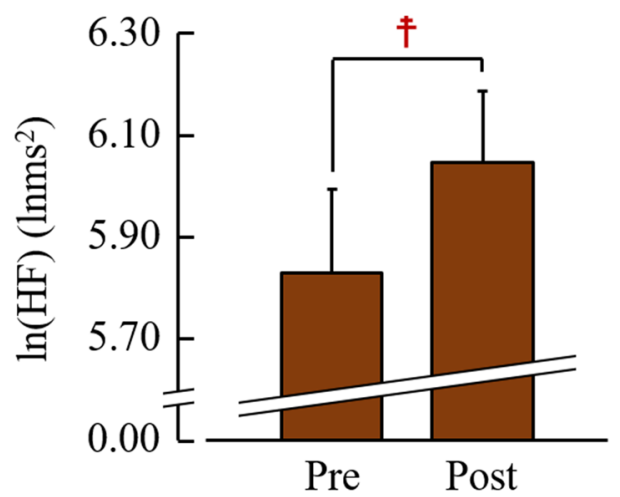

\section{b Sympathetic nervous activity}

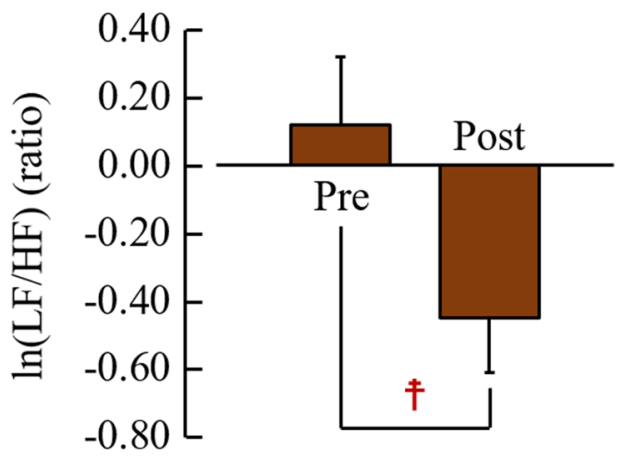

\section{aUzukuri wood}

Fig. 6 Pre- and post-measurement values of contact with uzukuri wood via the soles of the feet of parasympathetic and sympathetic nervous activities. a The natural logarithm of the high frequency (HF) power component of the heart rate variability. $n=27$, mean $\pm \mathrm{SE},+p<0.05$ (pre-measurement vs. post-measurement value) as determined using a paired t-test. $\mathbf{b}$ The natural logarithm of the low frequency/high frequency (LF/HF) of heart rate variability. $n=27$, mean $\pm \mathrm{SE},+p<0.05$ (pre-measurement vs. post-measurement value) as determined using a paired t-test 
mean baseline $\ln (\mathrm{HF})$ during the $30 \mathrm{~s}$ before contact did not significantly differ between each of the three materials $(p>0.05) . \ln (\mathrm{LF} / \mathrm{HF})$ was significantly decreased by touching the uzukuri wood compared with the premeasurement value $(0.12 \pm 0.20$ for pre-measurement, $-0.45 \pm 0.16$ for post-measurement; Fig. $6 b, p<0.05$ ). There were no significant differences found in the sanded wood $(-0.08 \pm 0.22$ for pre-measurement, $-0.20 \pm 0.18$ for post-measurement) and marble $(-0.43 \pm 0.25$ for pre-measurement, $-0.22 \pm 0.19$ for post-measurement) between, before, and after contact. Incidentally, the mean baseline $\ln (\mathrm{LF} / \mathrm{HF})$ during the $30 \mathrm{~s}$ before contact did not significantly differ between the three materials $(p>0.05)$.

\section{Psychological effects}

The results of subjective evaluation by the modified SD method are depicted in Fig. 7. With regard to "comfortable" feeling, the participants subjectively reported feeling "slightly to moderately comfortable" after touching the uzukuri and sanded wood and "slightly to moderately uncomfortable" after touching the marble. Therefore, contact with sugi wood was believed to induce significantly more comfort than contact with marble (Fig. 7a, $p<0.05$ ). With regard to "relaxed" feeling, the participants subjectively reported feeling "slightly to moderately relaxed" while touching the uzukuri wood, "indifferent to slightly relaxed" while touching the sanded wood, and "slight to moderately awakened" while touching the marble. Thus, sugi wood appears to have induced significantly more relaxation than marble (Fig. 7b, $p<0.05$ ). With regard to "natural" feeling, uzukuri wood was perceived as "slightly to moderately natural", sanded wood was perceived as "indifferent to slightly natural", and significantly more natural than marble, which was perceived as "moderately to very artificial" (Fig. 7c, $p<0.05$ ). Also, there was a significant difference in the natural feeling between the uzukuri and the sanded wood (Fig. 7c, $p<0.05$ ). With regard to "warm-cold" feeling, the participants reported feeling "indifferent to slightly warm" after contact with uzukuri or sanded wood and "moderately to very cold" after touching the marble. Thus, sugi wood was perceived as significantly warmer than marble (Fig. $7 \mathrm{~d}, p<0.05$ ). With regard to the "uneven-flat" feeling, uzukuri wood

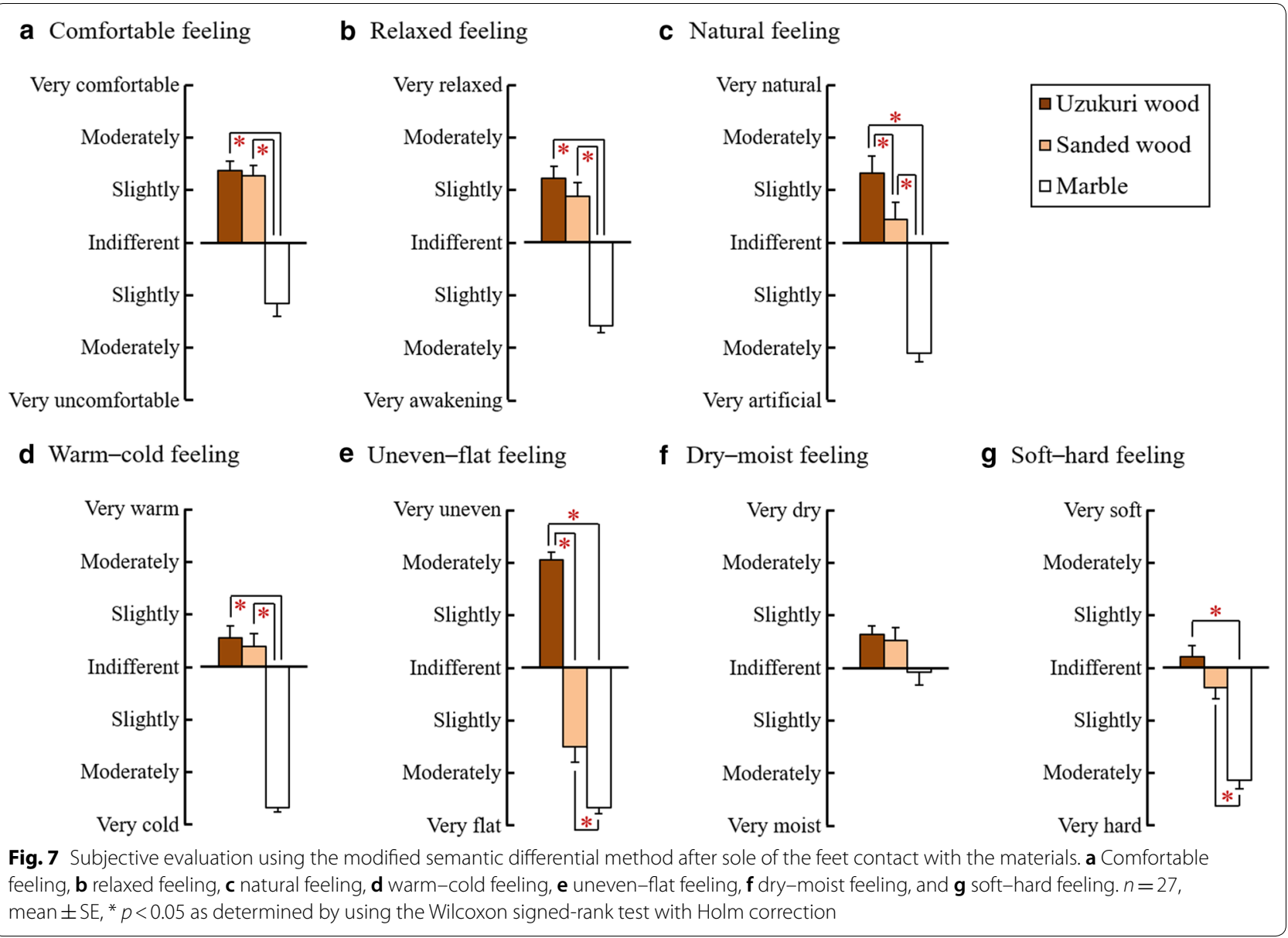


was perceived as approximately "moderately uneven" and significantly more uneven than sanded wood or marble (Fig. $7 e, p<0.05$ ). In addition, there was a significant difference in the "uneven-flat" feeling between sanded wood and marble (Fig. 7e, $p<0.05$ ). With regard to "soft-hard" feeling, uzukuri wood and sanded wood were perceived as "slightly soft to slightly hard", and significantly different from marble, which was perceived as "moderately to very hard" (Fig. $7 g, p<0.05$ ). For the "dry-moist" feeling, no significant differences were observed (Fig. 7f).

The POMS2 scores for the negative subscales A-H, C-B, $\mathrm{D}-\mathrm{D}$, and T-A were significantly lower, and the positive subscales V-A and F were significantly higher after touching the uzukuri or sanded wood rather than touching the marble (Fig. 8, $p<0.05$ ). F-I was significantly lower after touching the uzukuri wood than after touching the marble (Fig. 8, $p<0.05$ ). TMD was significantly lower after touching the uzukuri or sanded wood than after touching the marble, and lower after touching the uzukuri wood than touching the sanded wood (Fig. 8, $p<0.05$ ).

\section{Discussion}

The overall mean values significantly indicated that touching uzukuri wood significantly decreased the oxy$\mathrm{Hb}$ concentration in the left prefrontal cortex compared with marble (control). Furthermore, compared with the oxy-Hb concentrations before contact, contact with uzukuri wood showed significantly decreased oxy$\mathrm{Hb}$ in the right prefrontal cortex, increased $\ln (\mathrm{HF})$, and decreased the $\ln (\mathrm{LF} / \mathrm{HF})$ ratio. Moreover, contact with the sanded wood significantly decreased oxy-Hb concentrations in the right prefrontal cortex compared to before contact. The impression evaluation using the SD method and the mood evaluation via a shortened version of POMS2 found a significant difference between the sugi with uzukuri and the sanded finish or marble that exhibited a positive correlation with the physiological responses.

The effects of prefrontal activity revealed that the oxy$\mathrm{Hb}$ concentrations of the left and right prefrontal cortices were significantly decreased while touching uzukuri and the sanded wood with the sole of the feet. In a previous study, we reported that the oxy- $\mathrm{Hb}$ and total $\mathrm{Hb}$ concentrations of the prefrontal cortex were significantly decreased while touching the hinoki with the soles of the feet [16]. Hoshi et al. [28] demonstrated that pleasant feelings decreased oxy- $\mathrm{Hb}$ concentrations, and unpleasant feelings increased these levels in the prefrontal cortex during a screen image study. Therefore, we considered that significant decreases in oxy-Hb during sole of the feet contact with uzukuri and the sanded wood in this study reflected the physiological relaxation effects of sugi wood.

The effects to autonomic nervous activity, $\ln (\mathrm{HF})$, which is an index of parasympathetic nerve activity, significantly increased, and $\ln (\mathrm{LF} / \mathrm{HF})$, which is an index of sympathetic nerve activity, significantly decreased with tactile stimulation to the sole of the feet using uzukuri wood. Previous reports utilizing the uzukuri finish, have reported that similar effects can be obtained by palm contact with sugi [11], and sole and palm contact with hinoki $[12,16]$. The current study found that physiological relaxation effects could be obtained by sole of the feet contact with uzukuri sugi wood.

In this study, we used sugi, which is a typical softwood in Japan, with two types of finish: uzukuri finish and sanded finish. Uzukuri finish is one of the traditional

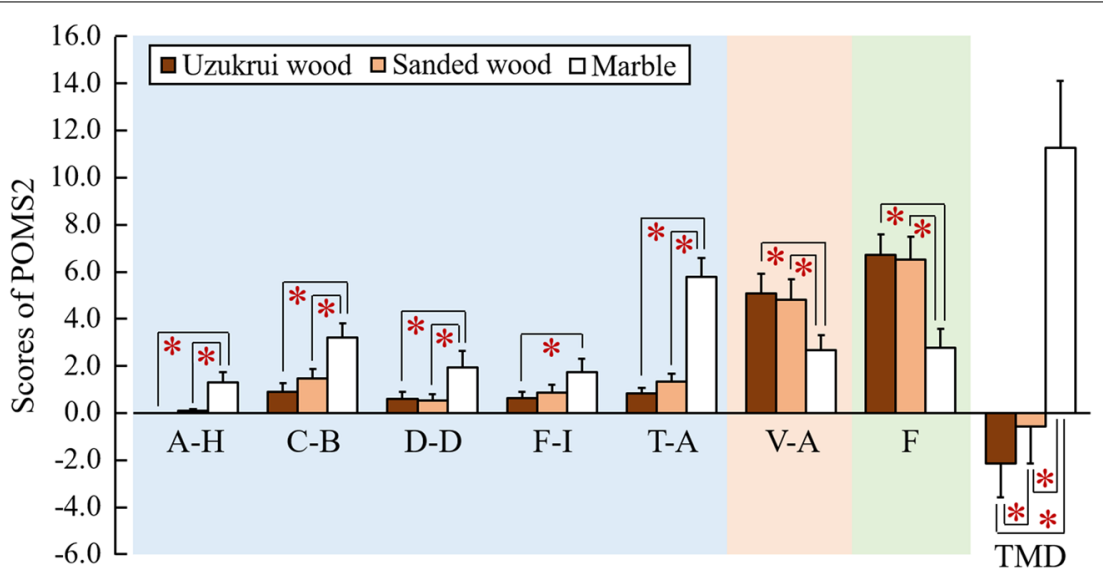

Fig. 8 Subjective feelings using the Profile of Mood States Second Edition after sole of the feet contact with the materials. $n=27$, mean $\pm S E$, * $p<0.05$ as determined by using the Wilcoxon signed-rank test with Holm correction. A-H anger-hostility, C- $B$ confusion-bewilderment, $D-D$ depression-dejection, F-I fatigue-inertia, T-A tension-anxiety, V-A vigor-activity, F friendless, TMD total mood disturbance 
surface finishing methods in Japan and has been used in previous studies that have confirmed the induction of physiological relaxation effects. The sanded finish is a more typical surface finishing method where the wood typically used for desks, furniture, and floors is sanded to a smooth finish. However, sanded finish wood had not yet been studied for the physiological effects of contact with the soles of the feet prior to this study. The physiological indices showed no significant differences between the uzukuri and sanded finish. While, the subjective evaluation, found significant differences in the subjective "natural" and "uneven-flat" feelings via the SD method and TMD scores by POMS2. Therefore, these results showed that the uzukuri finish was more natural and uneven and improved a negative mood state compared to the sanded finish.

In this study, the physical properties and the subjective evaluation of the specimen assessed revealed good correspondence. The thermal conductivity values of each specimen had a good agreement with the subjective evaluation of "warm-cold" using the modified SD method; the surface roughness values of each specimen were consistent with the subjective evaluation of "uneven-flat". However, the relationship between physical properties and physiological responses is an important issue that should be assessed in the future.

Miyazaki has advocated a "back to nature" theory [44, 45]. In this theory, he claims that human physiological functions are adapted to a natural environment because human evolution began from a subset of primates who lived in a natural environment until evolving into our current form approximately $6-7$ million years ago [46]. Less than $0.01 \%$ of the course of human existence has been in an urban environment, which started with the beginning of urbanization in the Industrial Revolution. From this viewpoint, the highly urbanized and artificial environments that we currently inhabit are the root cause of the "stress state" of modern people. Therefore, we enter a comparatively relaxed state when exposed to the natural environment or to nature-derived stimulation, which may increase our sense of being closer to our original natural state $[3,44,47]$. Wood is a common natural material, which we are in contact with daily, and it is used for manufacturing. When used as a flooring material, the main part of the human body that touches the wood is the soles of the feet, and the results of this current study suggest that contact with wood could be effective in relieving stress in the modern society. The novel features of this study are that it evaluated the physiological effects of tactile stimulation on the sole of the feet, for which there is limited data. This study focused on sugi wood, which is the most famous wood in Japan and has not been evaluated in previous studies. Furthermore, the simultaneous measurement of the prefrontal cortex activity and sympathetic/parasympathetic nervous activity enabled us to examine the possible relaxation effects imparted by touching this wooden material.

Recently, there has been increased interest in the application of natural therapies for people exposed to highstress conditions on a daily basis, and researchers have begun to accumulate data on this subject $[48,49]$. In the future, the physiological relaxation effects of wood imparted to humans will need to be examined for people under daily stress who have experienced injury or illnesses, such as spinal cord injury, elderly rehabilitation patients, and depression patients.

\section{Limitations of this study}

Firstly, this study used uncoated sugi wood; therefore, future studies should determine the physiological effects of touching sugi by utilizing various types of coatings because most wooden objects used in everyday life are coated. Secondly, this study measured the physiological effects of touching wood with only the soles of the feet. It will be necessary to clarify the physiological effect of more active forms of contact, such as stroking the surface of the wood with the foot or hand. Finally, the study population comprised only of young, healthy women in their 20s. To generalize these findings, further studies based on a larger, more varied sample population are required. For example, evaluating differences in the effects between young males and females in their 20 s as well as between various age groups.

\section{Conclusions}

This study found that tactile stimulation to the sole of the feet induced by touching sugi with the uzukuri finish resulted in calmer left prefrontal cortex activity as compared with contact with marble. Furthermore, tactile stimulation induced by touching sugi with the uzukuri finish resulted in higher parasympathetic nervous activity and lower sympathetic nervous activity as compared with contact with before contact. Also, tactile stimulation induced by touching sugi of sanded finish resulted in calmer right prefrontal cortex as compared with contact with before contact. These findings indicated that tactile stimulation of the soles of the feet with sugi (the uzukuri and sanded wood finish) could effectively induce physiological relaxation effects.

\section{Abbreviations}

TRS: Near-infrared time-resolved spectroscopy; oxy-Hb: Oxyhemoglobin; HRV: Heart rate variability; HF: High frequency; LF: Low frequency; SD: Semantic differential; POMS2: Profile of mood state 2nd edition; T-A: Tension-anxiety; D-D: Depression-dejection; A-H: Anger-hostility; F-I: Fatigue-inertia; C-B: 
Confusion-bewilderment; V-A: Vigor-activity; F: Friendliness; TMD: Total mood disturbance.

\section{Acknowledgements}

This paper is an achievement of the "physiological effects of visual and tactile stimulation by solid wood" commissioned from the Tokyo log wholesalers' association. We would also like to express our gratitude to Maruhon, Inc. who provided sugi and marble samples and performed the surface processing of the samples. We are grateful to Tatsuya Shibusawa, Kohta Miyamoto, Kiyohiko Fujimoto, and Yukari Matsumura of the Forestry and Forest Products Research Institute for their guidance in the measurement of the physical property values. We are grateful to Hiromitsu Kobayashi of the Ishikawa Prefectural Nursing University for his contribution of analyzing the HRV signals to estimate the respiratory rate.

\section{Authors' contributions}

YM contributed to the study conceptualization. HI and YM contributed to study design. HI performed data collection. HI performed statistical analysis and interpretation under the supervision of YM. HI wrote the first draft of the manuscript. YM substantially contributed to the interpretation of the data and provided important manuscript revisions. All authors approved the final vision of the manuscript. Each author also agreed to be accountable for all aspects of the work. All authors read and approved the final manuscript.

\section{Funding}

This work was performed as part of a research project funded by Tokyo Log Wholesalers' Association.

\section{Availability of data and materials}

The datasets used and/or analyzed during the current study are available from the corresponding author on reasonable request.

\section{Ethics approval and consent to participate}

This study was conducted in accordance with the Declaration of Helsinki and adhered to the regulations set by the Ethics Committee of the Center for Environment, Health, and Field Sciences, Chiba University, Japan (Project Identification Code Number 34). This study is registered in the University Hospital Medical Information Network of Japan (Unique ID issued by UMIN: UMIN000032808).

\section{Competing interests}

The authors declare that they have no competing interests.

\section{Author details}

${ }^{1}$ Center for Environment, Health and Field Sciences, Chiba University, 6-2-1 Kashiwa-no-ha, Kashiwa, Chiba 277-0882, Japan. ${ }^{2}$ Forestry and Forest Products Research Institute, 1 Matsunosato, Tsukuba, Ibaraki 305-8687, Japan.

\section{Received: 9 January 2020 Accepted: 10 April 2020}

Published online: 22 April 2020

\section{References}

1. Brod C (1984) Technostress: the human cost of the computer revolution. Addison Wesley, Boston

2. Lederbogen F, Kirsch P, Haddad L, Streit F, Tost H, Schuch P, Wüst S, Pruessner JC, Rietschel M, Deuschle M, Meyer-Lindenberg A (2011) City living and urban upbringing affect neural social stress processing in humans. Nature 474:498-501

3. Song C, Ikei H, Miyazaki Y (2016) Physiological effects of nature therapy: a review of the research in Japan. Int J Environ Res Public Health 13:781

4. Jo H, Song C, Miyazaki Y (2019) Physiological benefits of viewing nature: a systematic review of indoor experiments. Int J Environ Res Public Health. 16:4739

5. Ikei H, Song C, Miyazaki Y (2017) Physiological effects of wood on humans: a review. J Wood Sci 63:1-23

6. Miyazaki Y, Motohashi Y, Kobayashi S (1992) Changes in mood by inhalation of essential oils in humans II. Effect of essential oils on blood pressure, heart rate, $\mathrm{R}-\mathrm{R}$ intervals, performance, sensory evaluation and POMS (in Japanese with English abstract). Mokuzai Gakkaishi 38:909-913
7. Joung D, Song C, Ikei H, Okuda T, Igarashi M, Koizumi H, Park BJ, Yamaguchi T, Takagaki M, Miyazaki Y (2014) Physiological and psychological

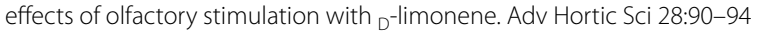

8. Ikei H, Song C, Lee J, Miyazaki Y (2015) Comparison of the effects of olfactory stimulation by air-dried and high-temperature-dried wood chips of hinoki cypress (Chamaecyparis obtusa) on prefrontal cortex activity. J Wood Sci 61:537-540

9. Ikei H, Song C, Miyazaki Y (2015) Physiological effect of olfactory stimulation by hinoki cypress (Chamaecyparis obtusa) leaf oil. J Physiol Anthropol 34:44

10. Ikei H, Song C, Miyazaki Y (2016) Effects of olfactory stimulation by a-pinene on autonomic nervous activity. J Wood Sci 62:568-572

11. Ikei H, Song C, Miyazaki Y (2019) Physiological effects of touching sugi (Cryptomeria japonica) with the palm of the hand. J Wood Sci 65:48

12. Ikei H, Song C, Miyazaki Y (2018) Physiological effects of touching hinoki cypress (Chamaecyparis obtusa). J Wood Sci 64:226-236

13. Ikei H, Song C, Miyazaki Y (2017) Physiological effects of touching wood. Int J Environ Res Public Health 14:801

14. Ikei H, Song C, Miyazaki Y (2017) Physiological effects of touching coated wood. Int J Environ Res Public Health 14:773

15. Mertz M (2016) 6.2. Techniques for enhancing the beauty of wood: wood and traditional woodworking in Japan, 2nd edn. Kaiseisha Press, Otsu

16. Ikei H, Song C, Miyazaki Y (2018) Physiological effects of touching the wood of hinoki cypress (Chamaecyparis obtusa) with the soles of the feet. Int J Environ Res Public Health 15:2135

17. Ministry of Agriculture, Forestry and Fisheries (2016) Trends in material supply and demand: Wood Supply and Demand Report. Statistics Department, Ministry of Agriculture, Forestry and Fisheries, Tokyo, Japan. http://www.maff.go.jp/j/tokei/kouhyou/mokuzai/index.html. Accessed 26 November 2019

18. Sakuragawa S, Kaneko T, Miyazaki Y (2008) Effects of contact with wood on blood pressure and subjective evaluation. J Wood Sci 54:107-113

19. ASTM C518-10 (2003) Standard test method for steady-state thermal transmission properties by means of the heat flow meter apparatus. ASTM, West Conshohocken

20. ISO 8301 (1991) Thermal insulation determination of steady-state thermal resistance and related properties heat flow meter apparatus. ISO, Geneva

21. Cui X, Bray S, Bryant DM, Glover GH, Reiss AL (2011) A quantitative comparison of NIRS and fMRI across multiple cognitive tasks. Nuerolmage 54:2808-2821

22. Boas DA, Elwell CE, Ferrari M, Taga G (2014) Twenty years of functional near-infrared spectroscopy: introduction for the special issue. Neuroimage $1: 1-5$

23. Seiyama A, Seki J, Tanabe HC, Sase I, Takatsuki A, Miyauchi S, Eda H, Hayashi S, Imaruoka T, Iwakura T, Yanagida T (2004) Circulatory basis of fMRI signals: relationship between changes in the hemodynamic parameters and BOLD signal intensity. Neuroimage 21:1204-1214

24. Ferrari M, Quaresima V (2012) A brief review on the history of human functional near-infrared spectroscopy (fNIRS) development and fields of application. Neuroimage 63:921-935

25. Torricelli A, Contini D, Pifferi A, Caffini M, Re R, Zucchelli L, Spinelli L (2014) Time domain functional nirs imaging for human brain mapping. Neuroimage 85:28-50

26. Ohmae E, Oda M, Suzuki T, Yamashita Y, Kakihana Y, Matsunaga A, Kanmura Y, Tamura M (2007) Clinical evaluation of time-resolved spectroscopy by measuring cerebral hemodynamics during cardiopulmonary bypass surgery. J Biomed Opt 12:9

27. Ohmae E, Ouchi Y, Oda M, Suzuki T, Nobesawa S, Kanno T, Yoshikawa E, Futatsubashi M, Ueda Y, Okada H, Yamashita Y (2006) Cerebral hemodynamics evaluation by near-infrared time-resolved spectroscopy: correlation with simultaneous positron emission tomography measurements. Neuroimage 29:697-705

28. Hoshi Y, Huang J, Kohri S, Iguchi Y, Naya M, Okamoto T, Ono S (2011) Recognition of human emotions from cerebral blood flow changes in the frontal region: a study with event-related near-infrared spectroscopy. J Neuroimaging 21:94-101

29. Task Force of the European Society of Cardiology and the North American Society of Pacing and Electrophysiology (1996) Heart rate variability: standards of measurement, physiological interpretation and clinical use. Circulation 93:1043-1065 
30. Kobayashi H, Ishibashi K, Noguchi H (1999) Heart rate variability; an index for monitoring and analyzing human autonomic activities. Appl Human Sci 18:53-59

31. Kanaya N, Hirata N, Kurosawa S, Nakayama M, Namiki A (2003) Differential effects of propofol and sevoflurane on heart rate variability. Anesthesiology 98:34-40

32. Sawada Y, Ohtomo N, Tanaka Y, Tanaka G, Yamakoshi K, Terachi S, Shimamoto K, Nakagawa M, Satoh S, Kuroda S, limura O (1997) New technique for time series analysis combining the maximum entropy method and non-linear least squares method: its value in heart rate variability analysis. Med Biol Eng Comput 35:318-322

33. Pagani M, Lombardi F, Guzzetti S, Rimoldi O, Furlan RA, Pizzinelli P, Sandrone G, Malfatto G, Dell'Orto S, Piccaluga E (1986) Power spectral analysis of heart rate and arterial pressure variabilities as a marker of sympatho-vagal interaction in man and conscious dog. Circ Res 59:178-193

34. Kobayashi H, Park BJ, Miyazaki Y (2012) Normative references of heart rate variability and salivary alpha-amylase in a healthy young male population. J Physiol Anthropol 31:9

35. Schäfer A, Kratky KW (2008) Estimation of breathing rate from respiratory sinus arrhythmia: comparison of various methods. Ann Biomed Eng 36:476-485

36. McCrady JD, Vallbona C, Hoff HE (1966) Neural origin of the respiratoryheart rate response. Am J Physiol 211:323-328

37. Kobayashi H (1998) Normalization of respiratory sinus arrhythmia by factoring in tidal volume. Appl Human Sci 17:207-213

38. Osgood CE, Suci GJ, Tannenbaum P (1957) The measurement of meaning University of Illinois Press, Urbana

39. Lin S, Hsiao YY, Wang M (2014) Test review: the profile of mood states 2nd edition. J Psychoeduc Assess 32:273-277

40. Yokoyama K, Watanabe K (2015) Japanese translation of POMS2: profile of mood states, 2nd edn. Kaneko Shobo, Tokyo (in Japanese)
41. Heuchert JP, McNair DM (2012) POMS2: profile of mood states, 2nd edn. Multi-Health Systems Inc, New York

42. McNair DM, Lorr M (1964) An analysis of mood in neurotics. J Abnorm Psychol 69:620-627

43. Victor A, Elsässer A, Hommel G, Blettner M (2010) Judging a plethora of $p$-values: how to contend with the problem of multiple testing. Part 10 of a series on evaluation of scientific publications. Dtsch Arztebl Int 107:50-56

44. Miyazaki Y (2018) Shinrin-yoku: the Japanese way of forest bathing for health and relaxation. Octopus Publishing Group, London

45. O'Grady MA, Meinecke L (2015) Silence: because what's missing is too absent to ignore. J Societ Cult Res 1:1-25

46. Brunet M, Guy F, Pilbeam D, Mackaye HT, Likius A, Ahounta D, Beauvilain A, Blondel C, Bocherens H, Boisserie JR, De Bonis L (2002) A new hominid from the Upper Miocene of Chad, Central Africa. Nature 418:141-151

47. Hansen MM, Jones R, Tocchini K (2017) Shinrin-Yoku (forest bathing) and nature therapy: a state-of-the-art review. Int J Environ Res Public Health 14:851

48. Ochiai H, Song C, Ikei H, Imai M, Miyazaki Y (2017) Effects of visual stimulation with bonsai trees on adult male patients with spinal cord injury. Int J Environ Res Public Health 14:1017

49. Song C, Ikei H, Nara M, Takayama D, Miyazaki Y (2018) Physiological effects of viewing bonsai in elderly patients undergoing rehabilitation. Int J Environ Res Public Health 14:2635

\section{Publisher's Note}

Springer Nature remains neutral with regard to jurisdictional claims in published maps and institutional affiliations.

\section{Submit your manuscript to a SpringerOpen ${ }^{\circ}$ journal and benefit from:}

- Convenient online submission

- Rigorous peer review

- Open access: articles freely available online

- High visibility within the field

- Retaining the copyright to your article

Submit your next manuscript at springeropen.com 